\title{
Rethinking Social and Economic Development: Promoting Digital Literacy
}

\author{
Shahram Amiri \\ Stetson University, DeLand, FL, USA
}

\section{samiri@stetson.edu}

\begin{abstract}
Today's digital divide that separates the "haves" and the "have nots" is attributed in part to geography, race, income, employment, age, gender, and education. Not only do some segments of the population remain unconnected, but these sectors also have no desire to connect. Thus, the connected portions of the world must create an urge and necessity to connect so that even the most remote location can access the same information as countries with technological enrichment. The first step towards worldwide connectivity involves worldwide understanding, achieved through information literacy, therefore allowing each person to become an independent, self-sufficient user. These characteristics lead to a better education, where the user can reap the benefits of schooling and life experience because of information literacy skills. The most important reward is an overall improved life where the Internet no longer separates people, but instead brings them together for work, communication, and leisure. These goals can only be accomplished through a collaborative effort involving both those connected, and those not connected. Without cooperation from both sides, the digital divide will continue existing.
\end{abstract}

Keywords: digital divide, digital inclusion, information literacy, social responsibility, education, connectivity

\section{Introduction}

Around the world, a divide exists between those at the forefront of the digital revolution and those remaining at the rear. Many times the areas lingering behind do not just lag solely in terms of Internet use but "...more than 80 [percent] of the world's population has never heard a dial tone, let alone surfed the web (Black, 1999)." Thus, we must engage in worldwide connectivity, also referred to as digital inclusion where "increasing the number of Americans using the technology tools of the digital age is a vitally important goal," (Economics and Statistics Administration, 2000). This goal encourages all parts of the world to utilize the Internet as a tool for advancement, so that no area has more access than another area. Though the last six years have shown an increase in digital inclusion worldwide, with Internet usage increasing from 1.3 percent to 9.0 percent we must not celebrate the accomplishments yet, but instead continue striving for worldwide connectivity (Internet Software Consortium, 2002).

Even within the United States, only fifty-four percent of the nation connects to the Internet, leaving almost half of the nation in a digital abyss. Those connected, both inside and outside of the United States,

Material published as part of these proceedings, either on-line or in print, is copyrighted by Informing Science. Permission to make digital or paper copy of part or all of these works for personal or classroom use is granted without fee provided that the copies are not made or distributed for profit or commercial advantage AND that copies 1) bear this notice in full and 2) give the full citation on the first page. It is permissible to abstract these works so long as credit is given. To copy in all other cases or to republish or to post on a server or to redistribute to lists requires specific permission from the publisher at Publisher@InformingScience.org must help keep the percentage of connected ind $i-$ viduals on the rise and narrow the digital divide between the "haves" and the "have nots," (Economics and Statistics Administration, 2002). The boundaries between those who can and cannot connect to the Internet come in the form of geography, race, income, and education. Lack of access does not represent the sole reason for the unconnected population. Many times the lack of 
motivation to learn application of the Internet keeps unconnected groups underserved. To redress this problem, groups lacking connectivity must learn the importance of information literacy. Underserved areas can utilize information literacy to discover that accessing information leads to increased education. Accessing information also leads to a better quality of life which, in a global economy, represents a goal most people strive for. To help reach that goal, the connected portion has a responsibility to show the underserved population the advantages in being Internet savvy because those connected have already experienced the numerous benefits the Internet can have.

\section{The Digital Chasms}

\section{Geographic Boundaries}

Although great advances have been made in rural connectivity in recent years, with the gap between rural and urban households owning a computer going from three percent in 1998 to almost two percent in 2000 (Econo mics and Statistics Administration, 2000), still more measures must be taken (Figure 1). At almost every income level, those households in rural areas are less likely to own computers than households in urban or central city areas due to cost and under development (Economics and Statistics Administration, 1999). In rural areas, people who used the Internet jumped from 29 percent in 1998 to 53 percent in 2001. Central city areas, however, have not kept up as well, with the rate of Internet use at 49 percent, while the national average sits at 54 percent (Wilhelm, Carmen, \& Reynolds, 2002).

In addition, less than five percent of towns of 10,000 or less have cable modem, while 65 percent of cities with populations over 250,000 have such service (Economics and Statistics Administration, 2000). This leaves 47 percent of the rural population unconnected (Economics and Statistics Administration, 2002). Many times the lack of connectivity can be attributed to the idea that rural communities often represent the agricultural section of the nation that denies the relevance of the Internet to their everyday lives (Richardson, 1997).

\section{Race/Ethnicity Confines}

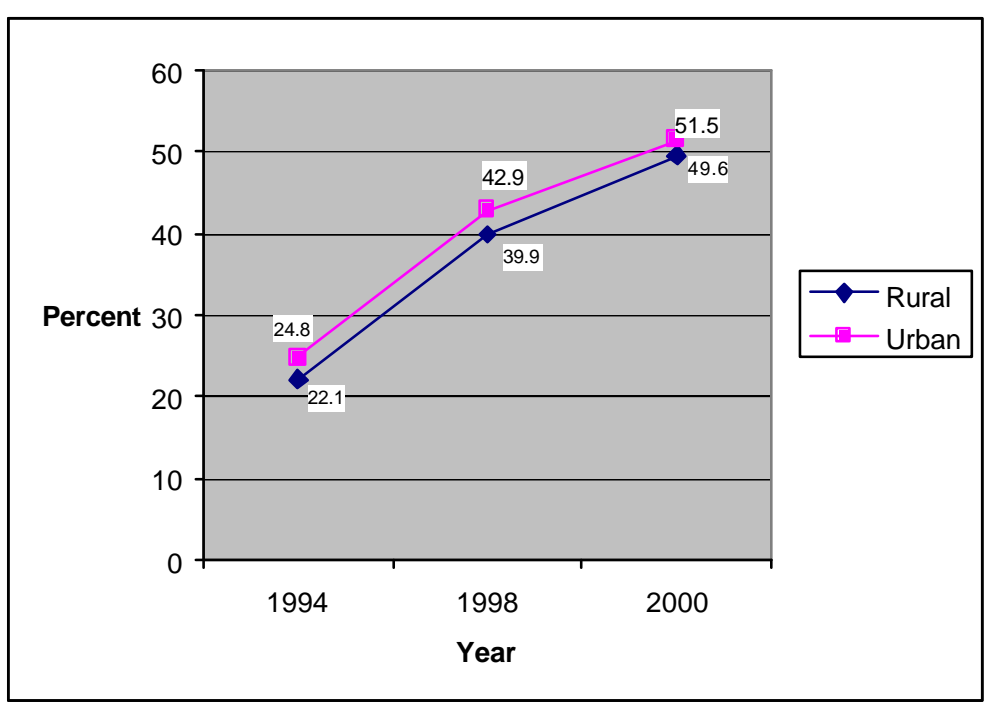

Figure 1: Percent of U.S. households with a computer

The digital divide between Whites and minorities runs deep because "Whites are more likely to have access to the Internet from home than Blacks or Hispanics have from any location (Economics and Statistics Administration, 1999)." Blacks lag behind Whites with a connectivity of 39.8 and 59.9 percent respectively. Hispanics show the least amount of connectivity with only 31.6 percent Internet users (Figure 2). The minority segment has made advances with Internet use among Blacks increasing at an annual rate of 31 percent during a three year time period and Internet use among Hispanics growing at a yearly rate of 26 percent. However, the Blacks and Hispanics have not yet reached the numbers of White connectivity. Without help and encouragement, these segments of the population will fall behind again and never reach the goal (Econo mics and Statistics Administration, 2002). 
African American institutions of higher learning illustrate the deepest scars of the digital divide; therefore this segment can also benefit the most from connectivity. In a report on historically black colleges and universities (HBCUs), none of the participating schools required computer ownership and only 15 percent recommended it. In non-HBCU institutions 30.5 percent recommend computer ownership. In addition, about 75 percent of students attending HBCUs do not own a computer and rely on institutional resources to connect to the Internet. Non-historically black college and universities account for one out of two students owning a computer (National Association for Equal Opportunity in Higher Ed ucation, October 2000).

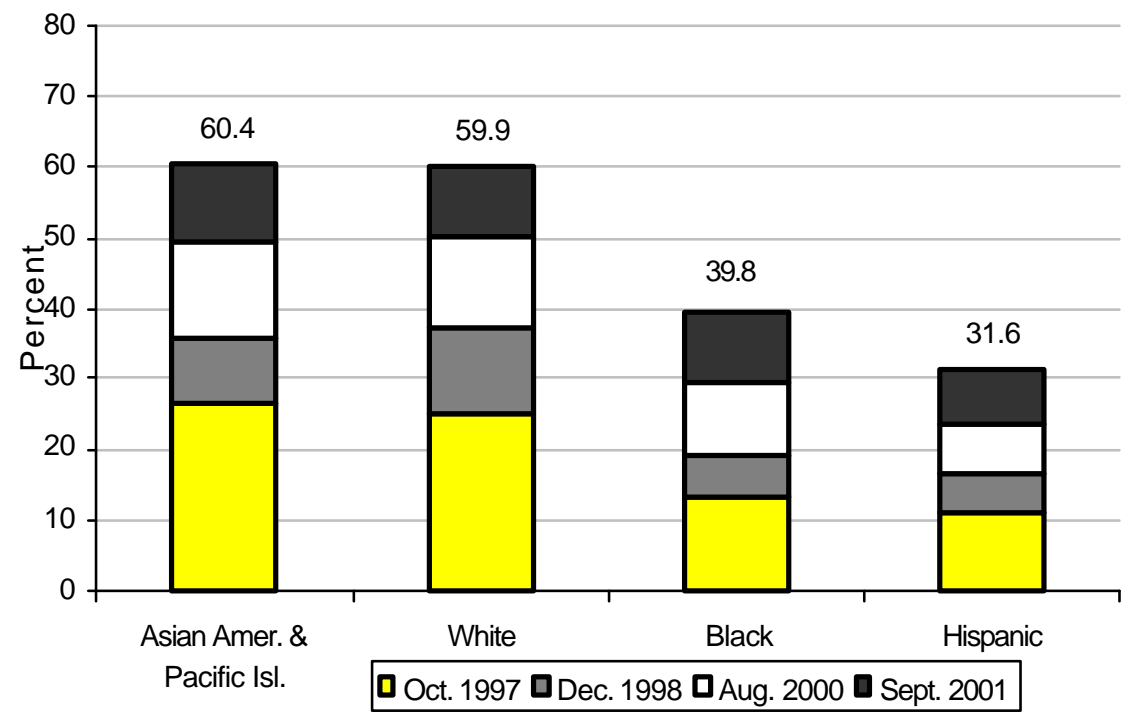

Figure 2: Internet use by race

Source: NTIA and ESA, U.S. Department of Commerce, using U.S. Census Bureau

Current Population Survey Supplements

\section{Income Limitations}

Over the past few years, the price of the Internet has decreased tremendously, allowing people who live in households with an income below $\$ 15,000$ to connect at an annual rate of 25 percent. Homes with incomes over $\$ 75,000$ only increase at a yearly rate of 11 percent. Table 1 shows that the under $\$ 15,000$ category has shown immense improvement, but still those with the lowest income have 25 percent of the population connected, while the $\$ 75,000$ group has 78.9 percent connected (Economics and Statistics Administration, 2002). Further problems exist because those in the lower income brackets less often use the Internet for word processing, school assignments, and other standard software education, and more often use connectivity to play games (Wilhelm, Carmen, \& Reynolds, 2002).

\section{Education Limitations}

People with all educational levels have been connecting to the Internet at a rapid pace. Internet use for adults with a Bachelor's degree grew at an annual rate of 13 percent during December 1998 to

\begin{tabular}{|c|c|c|c|c|}
\hline & $\mathbf{1 9 9 7}$ & $\mathbf{1 9 9 8}$ & $\mathbf{2 0 0 0}$ & $\mathbf{2 0 0 1}$ \\
\hline Less than $\$ 15,000$ & 9.2 & 13.7 & 18.9 & 25.0 \\
\hline$\$ 15,000-\$ 24,999$ & 11.6 & 18.4 & 25.5 & 33.4 \\
\hline$\$ 25,000-\$ 34,999$ & 17.1 & 25.3 & 35.7 & 44.1 \\
\hline$\$ 35,000-\$ 49,999$ & 22.8 & 34.7 & 46.5 & 57.1 \\
\hline$\$ 50,000-\$ 74,999$ & 32.3 & 45.5 & 57.7 & 67.3 \\
\hline$\$ 75,000 \&$ above & 44.5 & 58.9 & 70.1 & 78.9 \\
\hline
\end{tabular}

Table 1: Internet use by income 
September 2001. Internet use among those with only a high school diploma grew at an annual rate of 30 percent over the same period. However, those with education are still more likely to use the Internet. Figure 3 shows that only 12.8 percent of people with less than a high school education use the Internet, while 83.7 percent of people with degrees beyond a Bachelor's degree do so (Econo mics and Statistics Administration, 2002). Individuals with a Bachelor's degree or higher may be more apt to use the Internet because, "Better educated adults are more likely to use and become familiar with computers and the Internet at work or through their school experiences," (Economics and Statistics Administration,

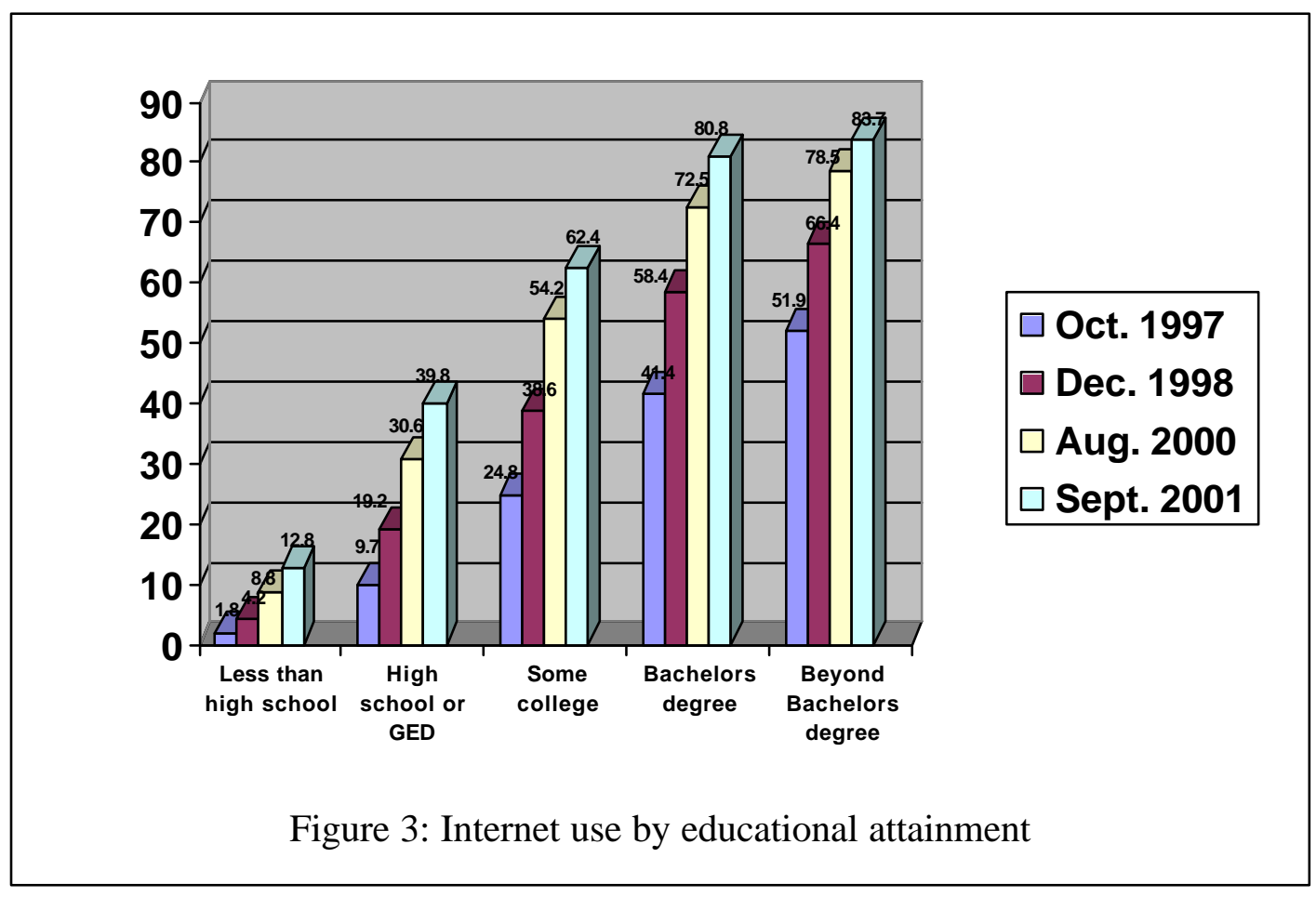

2000).

\section{Understanding before Connecting}

The first mission of those already connected involves establishing the desire for information literacy, or "the ability to locate, evaluate, and use information to become independent life-long learners," (Southern Association of Colleges and Schools, 1996). This goal must be started early in life, preferably in the school system. The presence of technology in a child's school environment aids in the development of information literacy. Children who have parents who possess information literacy can generally assist their children with developing essential skills. Likewise, information literacy in the classroom is crucial as well, and teachers can encourage information literacy by assigning homework that incorporates the use of a computer. Pre-college schools should take responsibility for educating the youth with the essential tools of information literacy because the sooner students realize the importance of information literacy, the sooner they will be able to apply this knowledge in a technological environment (Ba, Tally, \& Tsikalas, 2002).

The rewards gained by an information literate individual never cease, as they can use the Internet to locate information effectively and efficiently, evaluate critically and competently, and use information accurately and creatively. Those who gain the skills of information literacy become lifelong learners with increased motivation. The skills as a result of information literacy assist the lifetime process of selfimprovement and adaptation to changes. People who possess information literacy generally show more independence, therefore leading to a better learning experience in general because learners create their 
own initiative. This form of thinking increases interactivity and teaches individuals to question why things are the way they are, which provides a key tool: understanding.

Understanding proves imperative because individuals can then use knowledge based web resources to incorporate skills and continue participating in the workforce of tomorrow. The skills acquired through information literacy are essential to attract and nurture the entrepreneurial activity essential for economic progression (Digital Opportunity Task Force, 2002). Most importantly, understanding leads to developing intercultural communication that helps comprehend messages from other parts of the world. In order to make the Internet a useful tool worldwide, Internet users must understand some differences in other cultures and find a way to apply a portion of the seven billion web pages to their way of life. Information literacy facilitates this process by allowing people to understand the values and norms of cultures, as well as the messages of unfamiliar lifestyles. These unfamiliar lifestyles have a variety of uses for the Internet, and thus some web pages should pertain specifically to their particular interests instead of leaving this population in the dark. When Internet users can empathize with other cultures, they can help the unconnected nation see the importance of information literacy. The unconnected portion will realize through information literacy that the Internet offers relevant services that apply to everyday life.

\section{Access Leads to Improved Education}

An information literate individual creates the capacity to foster an improved education. Technology has increasingly become part of a child's education. As Figure 4 shows, by age 18, 90.1 percent of children use the Internet for schoolwork purposes (Economics and Statistics Administration, 2002).

Accessing information through technology gives children an opportunity to learn independently, simultaneously, and interactively, skills hard to attain through any other single medium. For example, computer savvy adults in rural areas can take a college course online. Likewise, residents of the United States can learn about other cultures by learning online, as did one participant of a digital investigation project who explained the wide-reaching effects the Internet pro-

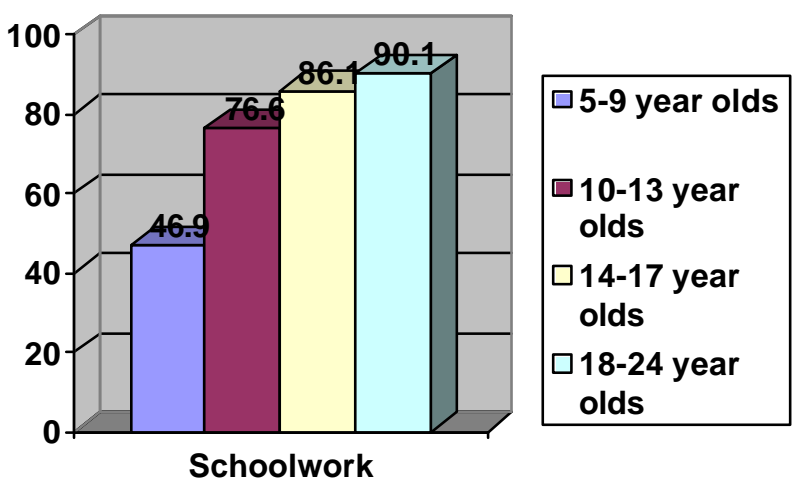

\section{Figure 4: Internet use for schoolwork} among those 5-24 vided her when she said, "We've visited the whole world...We can hear French radio to reinforce our French. There are books online. We can read the Constitution, or the Declaration of Independence. We study the Amendments and look right at them, (Ba, Tally, \& Tsikalas, 2002). The Internet provides information that libraries and the classroom may not offer. Students can append to their school lessons by looking up information online that may be more current than a classroom textbook. A student participating in the digital investigation project described recognized this when she said, "Today we've been studying slavery, so we had to go on the Internet to look up these web sites about stuff that we can't get [from textbooks]. Say we're studying modern-day slavery, so that's not in textbooks, so we have to look on the Internet and research different stuff like that," (Ba, Tally, and Tsikalas, 2002). By participating in a self-created curriculum like this, learners can seek personally developed goals while being guided by a teacher to maintain motivation.

The Internet serves as a tool for educational advancement by allowing students to share their ideas and work with others all over the nation and even the world. A 12-year-old Vermont student shared his ar- 
tistic expression despite the fact that he lived in an isolated part of the state (National Telecommunications and Information Administration, September 1999). Connectivity allowed him to take a class that was not offered at a nearby institution, but the student was still given the same advantages as a scholar who lived in the city. Likewise, a student in the United States can take a course in Italy without ever having to cross the Atlantic Ocean. This brings different communities together at a central venue to provide them with a variety of opportunities that would not be attainable if not for the Internet. Thus, cultures manage a better grasp on the needs of the rest of the world and can accordingly apply the Internet to these various societies so everyone can reap the benefits most suited to their desires.

The Internet also serves as an imperative tool for connecting all races and ethnicities, therefore improving education. For example, Historically Black Colleges and Universities can reap the rewards from a technologically connected system that allow the HBCUs to network with other schools so technological advancements can be made accordingly. Mass connectivity can allow HBCUs to grant students the same advantages they would get in an Ivy League environment (National Association for Equal Opportunity in Higher Education, 2000). With these new technological advancements and a new understanding of how to utilize the tools, HBCUs will produce the highest quality graduates. Once technology is understood through information literacy, the HBCUs can reap the benefits of technology and then pass their knowledge on to the rest of the Black community.

Overall, those who utilize connectivity experience enhancement of education. Internet users learn to question the information on the Internet and therefore gain a better understanding of culture. Students can then connect to foreign countries to participate in online discussions, learn at their own pace, check their status in real-time and participate in a wider variety of outlets for learning. With these opportunities available, students who use computers have shown improvements over those who do not. Computers in the home have been shown to improve scores in science and mathematics. Students who use computers for science can better understand concepts displayed on a graph shown on the computer screen, while those who use a computer for writing experience an attitude improvement towards self, teachers, and writing (Marshall, 2002). Students supplementing their education with a computer also have a stronger likelihood to stay home and off the streets (Ba, Tally, and Tsikalas, 2002). Thus, the Internet produces many positive outcomes for those using the computer at a young age, which, in turn, will allow the students to apply information literacy to circumstances that determine the rest of their lives.

\section{Access Equals a Better Quality of Life}

Along with digital inclusion, accessing information leads to a greater variety of services available to individuals who would not have the opportunity otherwise. For example, those who live hours from the nearest university can take online course to complete their education, which over three percent of Internet users do, as Figure 5 suggests (Economics and Statistics Administration, 2002). Some low-income homes have found that using the Internet can be a fast and easy way to access material concern housing, car sales, and other everyday information that these family may not have the time or money to do otherwise (Ba, Tally, and Tsikalas, 2002). Individuals concerned about medical conditions can first look up their ailments on the Internet before making repeated, and perhaps unnecessary, doctors visits, along with 34.9 percent of the population online (Economics and Statistics Administration, 2002). Another advantage of the Internet includes the expansion of available home health care which allows doctors and nurses to make electronic visits rather than home appointments, saving patients time and money (Leslie Harris \& Associates 2002). Once online information fits the needs of all countries, any area could access information and discover a new way of dealing with a disease like AIDS. In turn, areas that have already deve loped knowledge about certain health care issues can share this knowledge with the rest of the online community and thus increase the wealth of relevant and timely information available to those connected to the Internet (Digital Opportunity Task Force, 2002). 


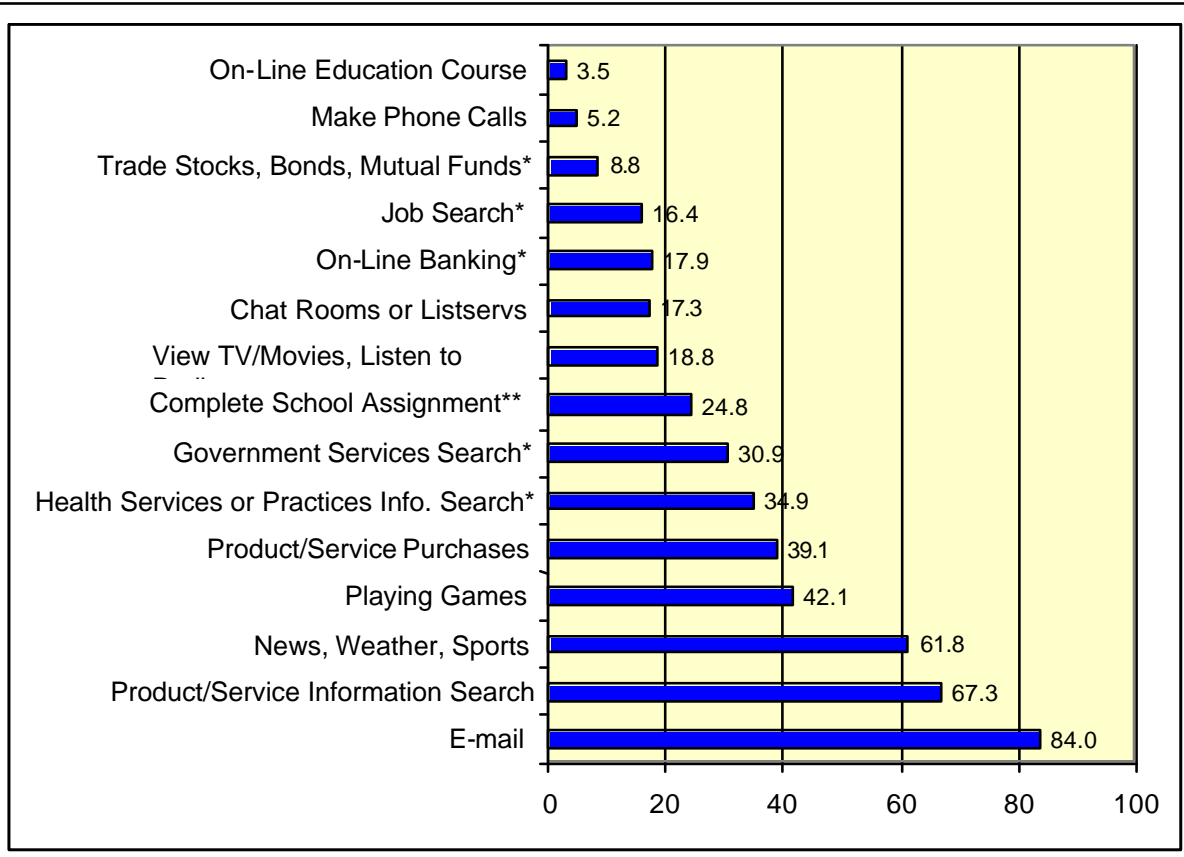

Figure 5: Activities of Individuals Online

*These online activities surveyed individuals age 15 and over only.

**This activity was asked of all respondents. If the response was restricted to individuals enrolled in school, the percentage of Internet users completing school assignments would increase to 77.5 percent.

Source: NTIA and ESA, U.S. Department of Commerce, using U.S. Census Bureau Current Population Survey Supplements

These changes can help government agencies, community groups, and other organizations deliver services to a wider variety of people more effectively and at a lower cost (Morino, 2000). Italy launched an e-government to help countries like Albania, Jordan, Mozambique, Nigeria, and Tunisia implement the use of information and communication technologies (ICTs) to transform currently existing governmental structures into instruments of growth (Digital Opportunity Task Force, 2002). The application of technology in underserved areas could lead to anything from "increased vaccination rates to improved job placement to higher test scores (Morino Institute, 2001)." By connecting the entire world to one central source of information, "The Internet also offers promise in the delivery of basic services like education and health information to far-flung regions, allowing a teacher or doctor in Ghana or Calcutta access to the same database information as on in London or New York (Norris, 2000)."

\section{Connected Nations Must Seize This Opportunity}

The United States has a prominent voice on the Internet with sixty five percent of the Web traffic in 2000 from the United States, as Figure 6 demonstrates (Flynn, 2000).

Therefore, the United States, along with G8 countries Canada, France, Germany, Italy, Japan, United Kingdom, and Russia, must make it a top priority to introduce technology to other nations who have yet to reap the technological rewards. The United Nations has also put together a committee, the United Nations Information Technology Service (UNITeS), to increase technological awareness around the world so that all nations can partake in the Internet. The leadership of UNITeS, the G8 countries, and non-governmental organizations (NGOs) should continue focusing on how technology can improve underdeveloped countries overall. On a smaller level, organizations, individuals, and agencies already using technology can strengthen collaboration among themselves to become better advocates for the representation of technology in other areas. For example, policymakers can help the effort by showing countries with no connectivity that technology can connect even the most remote location to the rest of the 
world to provide a wealth of opportunities. In addition, computer companies can help by supporting schools and families with little connectivity so these areas not only learn how to service the mselves, but soon service other areas as well. The more people involved in the effort, the more people there are available to help those with no connectivity. Any steps toward digital inclusion are steps in the right direction.

Inside connected nations too, areas that already utilize online access must pass the information and skills on to those unaware of the advantages the

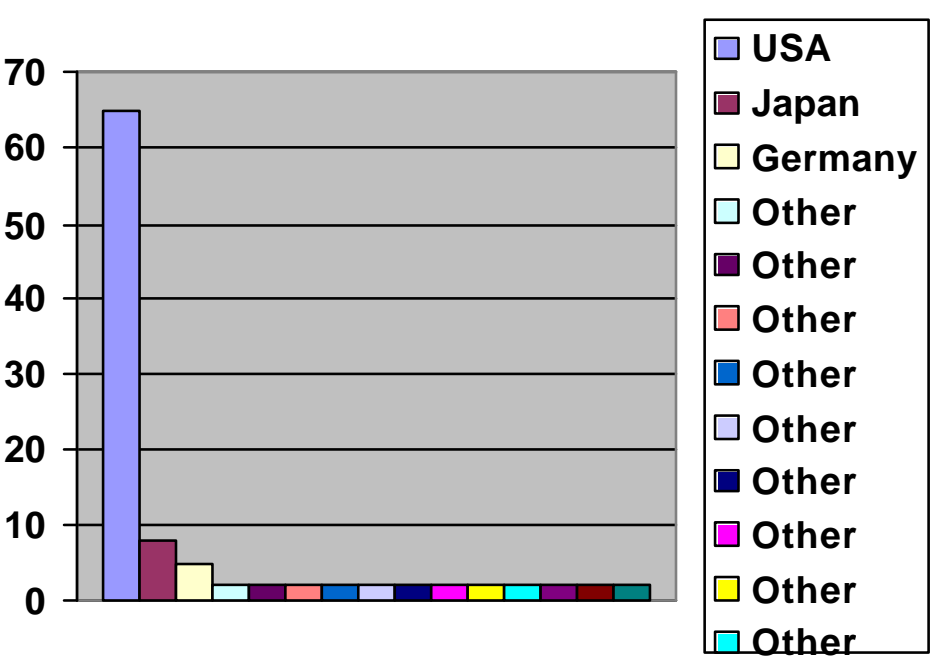

Figure 6: Worldwide web traffic Internet can have. All members of the connected community should work towards the goal of nationwide and worldwide inclusion. This includes students, teachers, parents, and community leaders. These individuals will act as local heroes, with the power, support and willingness to make changes. Rather than several small efforts, a few large efforts should exist to pass on information about Internet knowledge and information literacy. The underserved populace could then see how technology can benefit everyday life, despite geography, race, income, and education. Technology is really available to everyone, "it is simply a matter of our will (Web-Based Education Commission, 2000)."

This goal cannot be solved without a dramatic shift in thought on the part of the underserved population. Mass cooperation between those areas served and underserved remains integral in the search for widespread connectivity. Though the switch to a technological way of life may seem difficult at first, the result will be nationwide connectivity and understanding and eventually, hopefully, international digital inclusion. Through education and a positive attitude, people can realize that technology could help improve their quality of life.

\section{Conclusion}

The digital divide exists because some portions of the world utilize every feature of technology in order to improve life, while other parts of the world remain unsure about the usefulness of technology. Societies that have used the Internet to make advances must make certain to not leave the rest of the world population behind. We must realize that the cost of inaction proves far greater than the cost of the initiatives to enact programs for digital inclusion. Inaction would foster the digital divide and therefore make it harder to introduce technology at a later date. Now, while technology is still young, we must allow underdeveloped countries to see the importance in using the Internet to make not only individuals better, but the country as a whole. We must start in the countries that lag behind only somewhat because bringing technology in will be easier since a basis already exists. Once these countries learn how connectivity can be useful, they can spread the knowledge and skills to other countries. Likewise, a study with low-income and middle-income children discovered that middle-income children were best able to solve computer problems by seeking the assistance of a family member or friend. The family and friends of low-income children, however, did not have this advantage because they saw little need for a computer (Ba, Tally, \& Tsikalas, 2002). The more people who acquire digital literacy means an increased number available to teach others about this technological advancement. The amount of people will thus grow until eventually several different nations can exemplify the importance of information technology to underdeveloped nations. 
We cannot let the moment of opportunity pass us because the longer we wait, the longer we allow the digital divide to construct a digital chasm through the American population that will separate the "haves" and the "have nots" even further. If we leave this segment of society behind, we not only impoverish them, but we impoverish ourselves, our institutions of higher education, and the whole social, cultural, and economic order.

\section{References}

Ba, H., Tally, W., \& Tsikalas, K. (August 2002). Investigating Children's Emerging Digital Literacies. The Journal of Technology, Learning, and Assessment 1 (4), 1-48.

Black, J. (1999). Bridging the digital divide. BBC News. Retrieved June 27, 2002 from the World Wide Web http://news.bbc.co.uk/hi/english/special report/1999/10/99/information rich information poor/newsid 472000/472621. $\underline{\mathrm{stm}}$

Digital Opportunity Task Force. (June 2002). Report Card: Digital Opportunities for All. Retrieved Ju ly 15 from the World Wide Web http://www.dotforce.org/reports/documents/64/GeneratReport e.pdf

Economics and Statistics Administration and National Telecommunications and Information Administration. (November 1999). Falling Through the Net: Defining the Digital Divide. Washington D.C.: U.S. Department of Commerce.

Economics and Statistics Administration and National Telecommunications and Information Administration. (October 2000). Falling Through the Net: Toward Digital Inclusion. Washington D.C.: U.S. Department of Co mmerce.

Economics and Statistics Administration and National Telecommunications and Information Administration. (February 2002). A Nation Online: How Americans are Expanding Their Use of the Internet. Washington D.C.: U.S. Department of Commerce.

Flynn, M. K. (2000, January 12). Nations fear English language dominance on the net. CNN.com. Retrieved March 12, 2002 from the World Wide Web http://www.cnn.com/2000/TECH/computing/01/12/world.without.borders/index.html

Internet Software Consortium. (2002). Internet Domain Survey. Retrieved July 15, 2002 from the World Wide Web http://www.isc.org/ds/

Leslie Harris \& Associates. (July 2002). Bringing a Nation Online: The Importance of Federal Leadership. Retrieved July 23, 2002 from the World Wide Web http://www.civilrights.org/publications/bringinganationonline/nation1.html

Marshall, J. M. (May 2002). Learning with Technology: Evidence that Technology Can, and Does, Support Learning. San Diego, CA: San Diego State University.

Morino Institute. (July 2001). From Access to Outcomes: Raising the Aspirations for Technology Initiatives in Low-Income Communities. Retrieved February 8, 2002 from the World Wide Web http://morino.org/divides/report.pdf

Morino, M. (October 2000). Policy and Philanthropy: Keys to Closing the Digital Divide. Retrieved February 8, 2002 from the World Wide Web http://morino.org/advan sp div.asp

National Association for Equal Opportunity in Higher Education. (October 2000). Historically Black Colleges and Universities: An Assessment of Networking and Connectivity. Washington D.C.: U.S. Department of Co mmerce.

Norris P. (April 2000). The Worldwide Digital Divide: Information Poverty, the Internet and Development. Retrieved July 15, 2002 from the World Wide Web http://www.ksg.harvard.edu/iip/governance/psa2000dig.pdf

National Telecommunications and Information Administration. (September 1999). How Access Benefits Children: Connecting Our Kids to the World of Information. Washington D.C.: U.S. Department of Commerce.

Richardson, D. (1997). The Internet and Rural \& Agricultural Development: An Integrated Approach. Ontario, Canada: School of Rural Extension Studies.

Southern Association of Colleges and Schools. (1996). Criteria for Accreditation. Decatur, GA: Commission on Colleges.

Web-Based Education Commission. (December 2000). The Power of the Internet for Learning: Moving from Promise to Practice. Washington D.C.: U.S. Department of Education.

Wilhelm, T., Carmen, D., \& Reynolds, M. (June 2002). Kids Count Snapshot. Retrieved July 29, 2002 from the World Wide Web http://www.aecf.org/publications/pdfs/snapshot june2002.pdf 